\title{
OS SISTEMAS DE INFORMAÇÃO DOS SERVIÇOS DE ÔNIBUS DE BELO HORIZONTE SÃO SUFICIENTES PARA ORIENTAR E ATRAIR USUÁRIOS?
}

\section{ARE THE INFORMATION SYSTEMS OF THE BELO HORIZONTE BUS SERVICES ENOUGH TO ORIENT AND ATTRACT USERS?}

\author{
Raphael Freitas Souza ${ }^{1}$, Esp. \\ Cláudia Mont'Alvão ${ }^{2}$, D.Sc. \\ (1) Pontificia Universidade Católica do Rio de Janeiro \\ e-mail: raphael.freitassouza@gmail.com \\ (2) PPGDesign, Lab Ergodesign e Usabilidade de Interfaces LEUI PUC-Rio \\ e-mail:cmontalvao@puc-rio.br
}

Palavras chave: Sistema de Informação ao Usuário; transporte público por ônibus; Belo Horizonte.

A pesquisa consistiu no estudo dos sistemas de informação dos serviços de ônibus que atendem Belo Horizonte, MG, e na investigação das necessidades dos passageiros de se sentirem orientados e atraídos em utilizar o transporte. Foram aplicadas técnicas para levantar e consolidar tais necessidades, que servirão como subsídios ao desenvolvimento de novos sistemas. Foi constatado que além das informações em tempo real, do controle de todo trajeto pelo usuário e da boa usabilidade, é necessário que as interfaces contemplem outras informações, como segurança pública, conforto e atendimento.

\section{Key-words: User Information System; Bus Public Transport; Belo Horizonte}

The research consisted in studying the information systems of the bus services that serves Belo Horizonte, $M G$, and the inquiry of the real necessities of passengers to feel oriented and attracted to use the transport. Some techniques were carried out to collect and understand user needs that will be valuable in the design process of new information system. It was observed that besides the real-time information, user control along the route, and the good usability, it's necessary that the interfaces include another kind of information as, public safety, comfort and costumer service.

\section{Introdução}

Dentro do planejamento urbano e do equilíbrio nas comunidades, estão questões ligadas à mobilidade e à garantia do acesso às informações de deslocamento à maior parcela possível da população. A presença de um bom Sistema de Informação ao Usuário (SIU) na rede de 


\section{$16^{\circ}$ ERGODESIGN USIHC CINAHPA}

$16^{\circ}$ Ergodesign - Congresso Internacional de Ergonomia e Usabilidade de Interfaces Humano Tecnológica: Produto, Informações Ambientes Construídos e Transporte

$16^{\circ}$ USIHC - Congresso Internacional de Ergonomia e Usabilidade de Interfaces Humano Computador

CINAHPA | 2017 - Congresso Internacional de Ambientes Hipermídia para Aprendizagem. transportes pode melhorar tanto a sua qualidade quanto sua imagem, afetando a atração e fidelização de usuários por possibilitar uma melhor compreensão e utilização. (LANZONI ET AL., 2011; SCHEIN, 2003). Por outro lado, a negligência quanto a essas questões e a pouca discussão com os usuários, resultam em sistemas de comunicação e orientação precários, com uma ausência de uma estrutura organizada de mapas e informações (WRIGHT, 2001; MINISTÉRIO DAS CIDADES, 2008).

Dessa forma, o entendimento de como a rede de transportes funciona e o conhecimento de toda população sobre a existência dos Sistemas de Informação, são comprometidos, tendo como consequência a não realização de até $21 \%$ de viagens ou a pouca exploração do transporte, com o usuário se limitando a utilizar somente as linhas que conhece (SCHEIN, 2003; WRIGHT, 2001).

O problema da informação citado, de acordo com Schein (2003) e o Ministério das Cidades (2008), reflete diretamente nas sucessivas quedas do número de usuários nos sistemas de transporte. Confirmando essa tendência, o CREA-MG (2014) aponta que na Região Metropolitana de Belo Horizonte (RMBH), a participação dos deslocamentos pelo transporte público metropolitano por ônibus, reduziu de $44 \%$ para $31 \%$ enquanto no transporte individual aumentou de $18 \%$ para $31 \%$, entre os anos de 2002 e 2012 .

\subsection{O transporte público em Belo Horizonte}

O transporte público por ônibus em Belo Horizonte é formado por dois sistemas: o metropolitano e o municipal. O primeiro, composto por linhas intermunicipais da RMBH, é gerenciado pela Secretaria de Estado de Transportes e Obras Públicas (SETOP), vinculada ao Governo de Minas Gerais. Já o segundo, é gerenciado pela Empresa de Transportes e Trânsito de Belo Horizonte S/A (BHTrans), com gestão de transportes e política tarifária independentes. Os dois sistemas possuem integração com o trem metropolitano (CREA-MG, 2014; SETOP ,2015).
Com o objetivo de otimizar e racionalizar o sistema metropolitano, foi implantado em 2008, nos 34 municípios da RMBH, o modelo troncoalimentação que transformou cerca de quase 800 linhas em sete redes integradas de transportes chamadas de RIT. Cada uma delas é formada por um sistema integrado de linhas troncais e alimentadoras através de terminais e estações de transferência (BARRA, 2011; SETOP, 2008).

Como parte do projeto, no ano de 2014, a SETOP, iniciou a operação do BRT Metropolitano- Bus Rapid Transit ou transporte rápido por ônibus, com a marca "Move", simultaneamente à inauguração do $B R T$ municipal de Belo Horizonte, cidade que iniciou a implementação do modelo troncoalimentação no ano de 1997 (BARRA, 2011; FREITAS, 2014; MINISTÉRIO DAS CIDADES, 2008).

De acordo com o CREA-MG (2014), apesar dos dois sistemas utilizarem os mesmos corredores de transportes e até compartilharem alguns terminais, operam em módulos diferentes, funcionando como sistemas sobrepostos sem nenhuma ligação entre eles, inclusive com identidades visuais diferentes. O entendimento dos dois sistemas nem sempre é claro, resultando na dificuldade de se buscar e ter uma informação precisa e confiável.

\subsection{Os sistemas de informação e as necessidades dos usuários}

O tipo da informação e a forma que são apresentadas ao usuário pelas interfaces de orientação, influenciam de forma muitas vezes determinante nos comportamentos relativos aos deslocamentos pelo transporte público e, por conseguinte, na confiança e motivação da população em utilizá-lo. Os usuários, de acordo com sua relação com a rede de transportes, terão diferentes necessidades de informação, que segundo Lanzoni et al. (2011), estes podem ser enquadrados em quatro grupos:

- Regulares em rota cotidiana: precisam de informações atualizadas das linhas que usam mesmo já sendo familiarizados; 


\section{$16^{\circ}$ ERGODESIGN USIHC CINAHPA}

- Regulares em rota nova: conhecem o sistema, mas precisam de informações da rede de transportes e seus itinerários;

- Potenciais: precisam de informações promocionais e básicas como tarifas, horários e rotas, por entenderem pouco do sistema;

- Turistas: precisam de informações mais completas por não conhecerem o sistema local.

Independente das necessidades de informação de cada usuário, é fundamental que o Sistema de Informação, cumpra quatro funções: Promocional - que se refere à melhora da imagem do transporte com a promoção dos motivos das viagens e destinos, e facilidades no sistema; de ensinamento - relacionada à como utilizar o transporte e as regras; operacional - que permite ao usuário planejar viagens e se informar de alterações na programação; e de moderação - que atua sobre o comportamento do usuário, reduzindo sua ansiedade e dando a ele controle de escolha das opções disponíveis (SILVA, 2000).

\section{Metodologia}

A pesquisa de natureza descritiva apresentada neste artigo, com foco nos usuários de interfaces dos sistemas de informação relativos ao transporte público, teve como objetivo estudar suas opiniões, preferências e atitudes, e como o fornecimento de informações influenciam os comportamentos relativos à busca de informações, planejamento e deslocamentos (GIL, 1995). O objetivo desse trabalho foi o de consolidar as informações necessárias aos usuários e disponibilizá-las. Tais informações serão fundamentais para o desenvolvimento de novos sistemas de informação, que poderão contemplar interfaces de aplicativos, websites ou totens de autoatendimento.

Foram utilizadas as seguintes técnicas para o levantamento das necessidades de informação pelo transporte: Entrevista Semiestruturada e Inquirição Contextual, baseado nas metodologias de Iida (2005), Unger e Chandler (2012) e HoltzBlatt e Beyer (1997). Foi realizada também de forma complementar, uma simulação de busca de $16^{\circ}$ Ergodesign - Congresso Internacional de Ergonomia e Usabilidade de Interfaces Humano Tecnológica: Produto, Informações Ambientes Construídos e Transporte

$16^{\circ}$ USIHC - Congresso Internacional de Ergonomia e Usabilidade de Interfaces Humano Computador

CINAHPA | 2017 - Congresso Internacional de Ambientes Hipermídia para Aprendizagem. informações do sistema de transportes intermunicipal da RMBH.

Baseado nos grupos de usuários do transporte público citados por Lanzoni et al. (2011), os participantes das técnicas foram escolhidos por amostra de conveniência, chamada também de casual por Iida (2005), sendo estudados dois perfis:

- Perfil A (regulares em rota nova): Usuários dos sistemas metropolitano e municipal de Belo Horizonte que fazem uso do transporte em alguns horários e rotas não habituais;

- Perfil B (potenciais ou turistas): Usuário exclusivamente do sistema municipal.

\subsection{Entrevista}

A Entrevista foi realizada com 11 participantes, com duas sessões piloto. Dos participantes, 7 deles eram do Perfil A, enquanto 4 do Perfil B. Foram aplicadas 20 perguntas, abordando assuntos relacionados ao sistema de transportes como:

- Contexto relacionado aos deslocamentos;

- Percepção da qualidade do sistema e das viagens, dentro do conceito de atratividade;

- Fatores que afetam o comportamento de utilização e o processo decisório;

- Busca pela orientação no dia-a-dia e o modo de planejar os deslocamentos;

- Relação com a tecnologia, interação digital, redes sociais e interação social.

\subsection{Inquirição Contextual}

A técnica seguinte, Inquirição Contextual, sendo uma combinação de Entrevista e Observação, de acordo com Unger e Chandler (2012), envolveu investigar como os usuários planejavam e buscavam as informações do transporte público por interfaces digitais como websites e aplicativos.

A técnica foi aplicada com 8 pessoas, sendo 2 aplicações consideradas pilotos. 6 eram do Perfil A enquanto 2 do B. Foi analisado uma situação em que o participante precisaria se deslocar para um compromisso em um lugar ou horários não habituais. Durante a aplicação, além da pergunta - 


\section{$16^{\circ}$ \\ ERGODESIGN USIHC CINAHPA}

$16^{\circ}$ Ergodesign - Congresso Internacional de Ergonomia e Usabilidade de Interfaces Humano Tecnológica: Produto, Informações Ambientes Construídos e Transporte

$16^{\circ}$ USIHC - Congresso Internacional de Ergonomia e Usabilidade de Interfaces Humano Computador

CINAHPA | 2017 - Congresso Internacional de Ambientes Hipermídia para Aprendizagem.
"Como você memoriza e registra as informações?"- foram feitas outras adicionais relacionadas com o que o usuário realizava. Foi adotado a relação de mestre-aprendiz, conforme HoltzBlatt e Beyer (1997), sendo pedido ao participante demonstrar sua forma de planejamento e orientação, realizando as ações, justificando e comentando verbalmente.

\subsection{Simulação da busca da informação no sistema metropolitano para um lugar desconhecido}

A dinâmica que também consistiu em uma combinação de entrevista e observação, foi aplicada com 5 participantes, sendo 3 do Perfil A e 2 do Perfil B. Foi pedido para realizarem uma busca de informações e planejarem o deslocamento para um lugar desconhecido, dentro de um cenário definido pelo moderador, utilizando o computador ou o celular. O objetivo foi verificar as dificuldades de entendimento do sistema de transportes intermunicipal da RMBH e de se encontrar informações relativas a ele.

\section{Resultados}

\subsection{Percepção do Sistema Tronco-Alimentador}

Começando pela percepção de qualidade do modelo tronco-alimentador adotado nos sistemas municipal e metropolitano, os participantes enxergaram pontos positivos e negativos. A vantagem mais apontada foi o fato de existir pistas exclusivas para os ônibus, resultando em maior rapidez e menor preocupação quanto ao trânsito, influenciando na decisão de se usar o transporte público em vez do individual. Já os principais motivos que desagradavam os passageiros foi o excesso de baldeação e os horários bastante reduzidos das linhas alimentadoras.

\subsection{Fatores de decisão}

Embora os sistemas de informação apontados não contemplassem informações sobre a qualidade dos veículos, das viagens e do sistema, foi verificado que de fato são questões capazes de influenciar o processo decisório, ou a desistência do transporte público. Os pontos mais citados foram:

- Segurança quanto aos locais de embarque e desembarque e de seu entorno, horário de utilização do transporte público e preocupação com assaltos a ônibus;

- Condições dos veículos como manutenção e limpeza; e de conforto nas viagens, como lotação, tipo de poltronas e ar-condicionado;

- Atendimento e disponibilidade de informar e ajudar dos funcionários;

- Segurança e conforto na direção pelo motorista, e seu comportamento;

- Conforto para situações do cotidiano que afetam a mobilidade, como carregar volumes, e acompanhar crianças e idosos;

- Precisão e confiabilidade nas informações como horários, itinerários, pontos de parada e deslocamentos a pé;

- Previsão de espera dos ônibus;

- Preferência de linhas já conhecidas e rotas em que o usuário se sente mais tranquilo, do que a mais prática e rápida;

- Controle de todo o trajeto pelo usuário;

- Opiniões e dicas de outros passageiros;

- Comunicação clara entre passageiros e os gestores com alterações de serviço e avisos de utilidade pública; facilidade de se fazer reclamações e acompanhar as solicitações.

Já em relação aos principais motivos de desistência da utilização do transporte público relacionados à informação, foram apontados:

- Insegurança tanto em relação à segurança pública quanto a ficar perdido e sem assistência;

- Longo tempo de espera pelo ônibus e de deslocamento, excesso de baldeações e caminho extenso a ser percorrido a pé;

- Irregularidades no atendimento e falta de previsão da regularização do serviço;

- Não entendimento de como funciona o sistema e de como obter suas respectivas informações;

- Dificuldade de se ter informações precisas e confiáveis; 


\section{$16^{\circ}$ \\ ERGODESIGN USIHC CINAHPA}

$16^{\circ}$ Ergodesign - Congresso Internacional de Ergonomia e Usabilidade de Interfaces Humano Tecnológica: Produto, Informações Ambientes Construídos e Transporte

$16^{\circ}$ USIHC - Congresso Internacional de Ergonomia e Usabilidade de Interfaces Humano Computador

CINAHPA | 2017 - Congresso Internacional de Ambientes Hipermídia para Aprendizagem.
- Desconhecimento da existência de uma rota;

\subsection{Planejamento e orientação}

Dos participantes, apenas dois afirmaram não realizar qualquer tipo de planejamento, os demais o fazem, sendo a maioria antes de iniciarem o deslocamento, para não dependerem da consulta a muitas informações no percurso ou se preocuparem com questões de segurança pública, com a disponibilidade da internet ou a duração da bateria do aparelho. Somente um usuário se orientou durante o percurso (Figura 01).
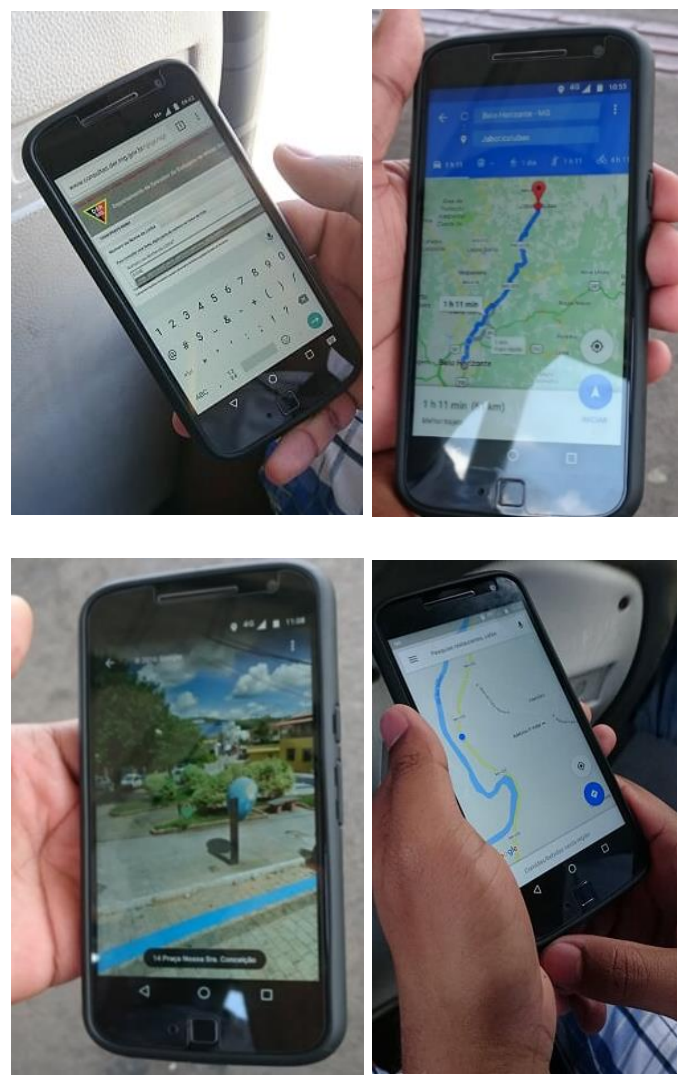

Figura 01 - Planejamento do usuário: Consulta ao site SETOP/DER-MG; visualização de percurso e monitoramento pelo Google Maps; visualização de imagens do destino pelo Street View. Fonte: os autores.

Na busca pela informação, a maioria prefere iniciala de forma independente, já que alegam não confiar plenamente na orientação de outras pessoas e afirmam que alguns funcionários do transporte não sabem informar corretamente. Mesmo assim, é bastante comum abordarem conhecidos, motoristas e outros usuários para a confirmação ou complementação de informações, e terem um maior sentimento de confiança em realizar os deslocamentos através da troca de opiniões.

Dos serviços de consulta de rotas, o Google Maps, nas versões desktop e mobile, foi o mais utilizado, com o uso complementar do Street View com as imagens do local de destino. O acesso desses serviços se dava diretamente pelo aplicativo ou encaminhado pelo buscador Google, sendo usado por alguns, o comando de voz.

Foi relatada e observada também a utilização de outros aplicativos e sites frequentemente usados em conjunto com os produtos Google como:

- SIU Mobile e o site da BHTrans com informações oficiais de linhas municipais;

- Site da SETOP/ DER-MG, para informações oficiais de linhas metropolitanas da RMBH;

- Sites de prefeituras;

- Sites de empresas de ônibus;

- Sites com informações não-oficiais.

\subsection{Busca de informações no sistema municipal de Belo Horizonte}

Na busca de informações pelo sistema municipal de Belo Horizonte, muitos usuários conseguiram encontrar as informações buscadas com facilidade, através dos produtos da Google, que apresentam informações precisas e a possibilidade de escolher rotas, cada uma contendo as trocas de ônibus, tempo de caminhada e de percurso.

O aplicativo SIU Mobile da BHTrans (Figura 02), foi elogiado pelos participantes por oferecer com precisão a previsão de tempo de espera dos coletivos em um determinado ponto de parada, afetando assim a forma de planejamento, e o processo decisório de rotas e de se utilizar o transporte público. Outro ponto observado foi a facilidade de se visualizar o itinerário e de se localizar todos os pontos de parada, pela numeração correspondente nos logradouros, presente também no site da BHTrans.

\section{Realização: "-) UNIVERSIDADE FEDERAL




\section{$16^{\circ}$ \\ ERGODESIGN USIHC CINAHPA}

Comparando as características dessas interfaces com as necessidades de informação levantadas pelos usuários, percebeu-se que os sistemas apesar de precisos - ainda não permitiam aos participantes sentirem-se confiantes sobre suas escolhas se considerados aspectos como segurança pública, conforto e qualidade, o que levava a uma troca de informações e opiniões com outras pessoas.

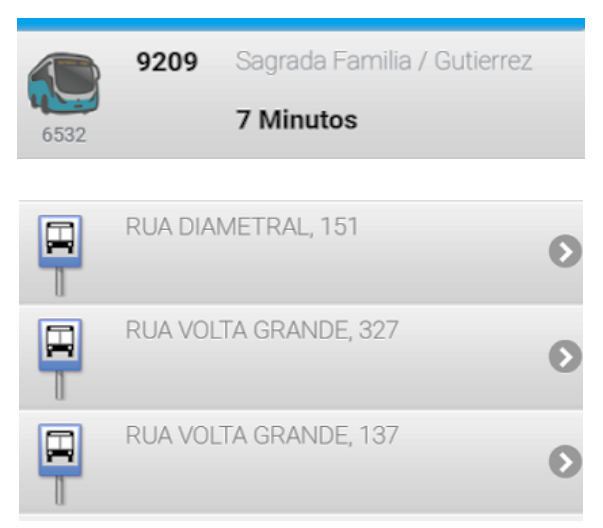

Figura 02 - Ap. SIU Mobile BH com a previsão de espera, número do veículo e pontos de parada. Fonte: SIU Mobile BH.

\subsection{Busca de informações no sistema intermunicipal metropolitano}

Na busca pelas informações do transporte intermunicipal metropolitano, primeiramente muitos dos usuários tiveram dificuldade em saber por onde inicia-la, inclusive aqueles que já usavam o sistema. O problema era agravado pelo fato do Google Maps não ter informações relativas a ele.

Quando os usuários recorriam a uma busca simples no Google, os sites relacionados como resultados (muitos deles não-oficiais), geravam dúvidas se as informações encontradas eram confiáveis e se estavam atualizadas. Outras vezes os participantes acessavam sites de prefeituras e de empresas de ônibus (Figura 3), e essas informações eram consideradas confusas e limitadas, dificultando o entendimento sobre a relação das linhas apresentadas e o atendimento ao destino pretendido. $16^{\circ}$ Ergodesign - Congresso Internacional de Ergonomia e Usabilidade de Interfaces Humano Tecnológica: Produto, Informações Ambientes Construídos e Transporte

$16^{\circ}$ USIHC - Congresso Internacional de Ergonomia e Usabilidade de Interfaces Humano Computador

CINAHPA | 2017 - Congresso Internacional de Ambientes Hipermídia para Aprendizagem.

O site da SETOP/ DER-MG que possui de fato informações oficiais de todas as linhas metropolitanas, não era de conhecimento de todos os usuários, principalmente daqueles que usavam exclusivamente o sistema municipal de Belo Horizonte. Alguns deles ficaram confusos entrando equivocadamente na seção de busca por linhas intermunicipais do interior do estado.

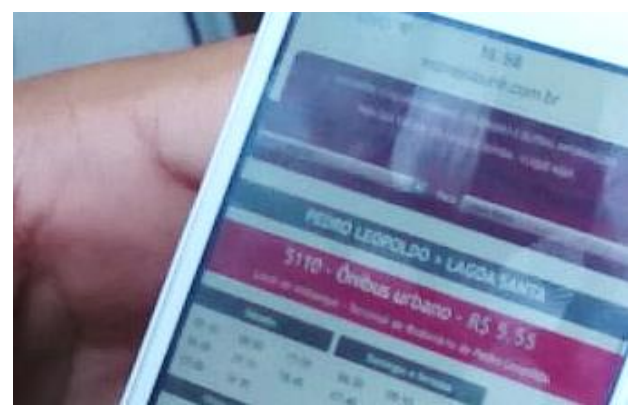

Figura 03 - Busca de informações de linhas operadas pelo Exp. Unir no site da empresa. Fonte: os autores.

O modo de busca no site também se mostrou ineficiente, uma vez que não existe uma maneira de se procurar as rotas por origem e destino. A busca se limitava a uma consulta em um banco de dados sendo que para se ter acesso às informações de horários, itinerários e pontos na região central, era preciso saber de antemão o número ou nome da linha (Figura 04). Não era possível, por exemplo, obter informações em tempo real da previsão de espera dos ônibus (como no SIU Mobile da BHTrans), a relação dos pontos de parada e os deslocamentos a pé.

Número ou Nome da Linha*
\begin{tabular}{|l}
\hline \\
\hline E0014 - AER. INTER. TANC. NEVES/EST. GOV. M. PINTO VIA F \\
\hline E1910 - ATENDIMENTO EMERGENCIAL ESTAÇÃO ELDORADO \\
\hline E1925 - ATENDIMENTO EMERGENCIAL ESTAÇÃO ELDORADO \\
\hline 1000 - TERM. TANCREDO NEVES/BAIRRO REGINA/BARREIRO \\
\hline 1100 - TERM. TANCREDO NEVES/PALMARES VIA J. C. OLIVEI \\
\hline 1110 - TERM. TANCREDO NEVES/WASHINGTON PIRES/LINDE \\
\hline 1111 - TERMINAL TANCREDO NEVES/W.PIRES/B.AMAZONAS/I \\
\hline 1120 - TERMINAL TANCREDO NEVES/SOL NASCENTE/TIROL/E \\
\hline 1130 - TERMINAL TANCREDO NEVES/PALMARES 1a. SECAO/E \\
\hline 1140 - TERMINAL TANCREDO NEVES/PALMARES 2a. SECAO/E \\
\hline 1150 - TERM. TANCREDO NEVES/DUVAL DE BARROS/FLAMEP \\
\hline 1180 - VILA IDEALTERMINAL TANCREDO NEVES
\end{tabular}

Figura 04 - A busca no site da SETOP/DER-MG, consiste em o usuário informar o número ou nome da linha ou procurar na lista. Fonte: SETOP/DER-MG. 


\section{$16^{\circ}$ \\ ERGODESIGN USIHC CINAHPA}

Foi constatada assim, a dificuldade de se obter informações rápidas, precisas e confiáveis, e de se entender o funcionamento do sistema e sua relação com o transporte municipal de Belo Horizonte. Os usuários demonstraram uma dependência maior de outras pessoas para se sentirem orientados e conseguirem informações básicas.

\subsection{Anotações dos resultados da busca}

A última etapa do planejamento após as consultas, para 6 dos participantes, consistiu em fazer registros das informações encontradas e das etapas dos deslocamentos. Os meios utilizados foram:

- Anotações em pedaços de papel de forma esquematizada, ou em agendas com o planejamento associado a compromissos;

- Impressão de mapas do destino e seu entorno;

- Anotações pelo aplicativo Google Keep, ou pelo Whatsapp, enviando para si próprio;

- Compartilhamento da pesquisa no Google Maps por e-mail para uma consulta posterior;

- Print-screen de telas com as informações.

Ao iniciar os deslocamentos, os usuários demonstraram e relataram efetuar ainda consultas ao celular durante o trajeto em alguns momentos, com o objetivo de monitorar ou alterar o seu planejamento inicial.

\subsection{Sugestões levantadas pelos usuários}

Durante todo o momento de aplicação das técnicas, em que os participantes manifestaram suas principais queixas e dificuldades com o Sistemas de Informação, foi também sugerido por eles, elementos que poderiam fazê-los mais orientados e confiantes em usar o transporte público como:

- Propagandas turísticas, oferecendo sugestões de rotas para pontos de interesse e acontecimentos da cidade;

- Critérios de resultado de buscas de rotas contemplando questões como segurança, conforto, qualidade e turismo;

- Imagens dos lugares de parada e do entorno; $16^{\circ}$ Ergodesign - Congresso Internacional de Ergonomia e Usabilidade de Interfaces Humano Tecnológica: Produto, Informações Ambientes Construídos e Transporte

$16^{\circ}$ USIHC - Congresso Internacional de Ergonomia e Usabilidade de Interfaces Humano Computador

CINAHPA | 2017 - Congresso Internacional de Ambientes Hipermídia para Aprendizagem.
- Informações de pontos de referência, hospitais, delegacias e estabelecimentos próximos;

- Informações da estrutura dos terminais, como plataformas, a existência de banheiros, lanchonetes, acessibilidade e as saídas;

- Explicação com clareza sobre o funcionamento dos sistemas de ônibus, metrô e as integrações;

- Interação com outros usuários com opiniões e avaliações e exibição de Índices de conforto, pontualidade, atendimento e segurança.

- Avisos de utilidade pública e alterações de serviço;

- Canal mais imediato e simples de comunicação entre passageiros e os órgãos gestores, facilitando o processo de uma reclamação.

\section{Conclusão}

Considerando as necessidades de orientação dos usuários desta pesquisa e as quatro funções dos Sistemas de Informação apontadas por Silva (2000), percebeu-se que ainda haviam diversas questões nos sistemas analisados, que afetavam a sua capacidade de oferecer orientação de modo suficiente para atrair e fidelizar usuários.

No sistema municipal de Belo Horizonte, as interfaces de orientação, segundo os participantes, foram consideradas satisfatórias, por serem oferecidos: o planejamento dos deslocamentos com a análise das etapas a pé e imagens dos locais; amplo controle do usuário; escolha e monitoramento de rotas; informações precisas em tempo real de espera dos coletivos; e informações completas de horários, itinerários e pontos de parada. Além disso, não foi relatado por nenhum usuário, dificuldade de entendimento do sistema. No entanto, a função promocional poderia ser melhor explorada com propagandas de rotas para pontos de interesse e eventos, e informações relativas à segurança púbica, o conforto dos veículos e a estrutura dos terminais.

Já quanto ao sistema metropolitano, foram percebidas deficiências severas na qualidade e apresentação da informação, a começar pela
Realização:

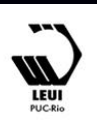


$16^{\circ}$ USIHC - Congresso Internacional de Ergonomia e Usabilidade de Interfaces Humano Computador

CINAHPA | 2017 - Congresso Internacional de Ambientes Hipermídia para Aprendizagem.

dificuldade de se obter um entendimento de seu funcionamento. Devido a precariedade do sistema de buscas e a escassez de informações, os usuários demonstraram grandes dificuldades em realizar o planejamento das viagens e ter controle e confiança sobre seus deslocamentos, sendo relatado como consequência, pouca atratividade e desistência frequente de se utilizar o transporte intermunicipal da RMBH.

Uma vez coletadas e organizadas essas informações, iniciou-se o desenvolvimento de sistemas que possam contemplar as necessidades dos usuários quanto ás informações buscadas para seu deslocamento por transporte público na RMBH. Acredita-se que o desenvolvimento de aplicativos, websites, e totens de informação, em conjunto, possam disponibilizar as informações necessárias de forma precisa, segura e confiável atendendo aos perfis de todos os usuários do sistema.

\section{Referências Bibliográficas}

BARRA, R. A. O impacto do transbordo em sistemas integrados de transporte coletivo por ônibus: uma análise quantitativa e qualitativa no município de Belo Horizonte. Dissertação (Mestrado). Universidade Federal de Minas Gerais, Escola de Engenharia, Belo Horizonte, 2011

CREA-MG - Conselho Regional de Engenharia e Agronomia de Minas Gerais. Mobilidade: Região Metropolitana de Belo Horizonte. Belo Horizonte: CREA-MG, 2014.

FREITAS, Bruno. BRT terá 10 terminais na Grande BH. Estado de Minas, Belo Horizonte, mar. 2014. Disponível em: $<$ http://www.em.com. br/app/noticia/gerais/2014/03/05/interna_gerais,50 4586/brt-tera-10-terminais-na-grande-bh.shtml> Acesso em: 25 out. 2016

GIL, Antonio Carlos. Métodos e técnicas de pesquisa social. 3.ed.São Paulo: Atlas,1991.207 p.

IIDA, Itiro. Ergonomia: Projeto e Produção - $2^{\circ}$ edição revista e ampliada. São Paulo: Edgard
Blucher, 2005.

HOLTZBLATT, Karen; BEYER, Hugh. Contextual Design: Defining Customer-Centered Systems. San Francisco: Morgan Kaufman Publishers, 1997.

LANZONI, C.; SCARIOT, C. A. ; SPINILLO, C. G.. Sistema de informação de transporte público coletivo no Brasil: algumas considerações sobre demanda de informação dos usuários em pontos de parada de ônibus. Infodesign (SBDI. Online), v. 8, p. 54-63, 2011.

\section{MINISTÉRIO DAS CIDADES. Manual de BRT}

- Bus Rapid Transit: guia de planejamento.

Brasília: Institute for Transportation and

Development Policy, 2008.

SCHEIN, Augusto Leonardo. Sistema de informação ao Usuário como Estratégia de Fidelização e Atração. 148f. Dissertação (Mestrado em Engenharia de Produção) - Escola de Engenharia, Universidade Federal do Rio Grande do Sul, Porto Alegre, 2003.

SETOP. Secretaria de Estado de Transportes e Obras Públicas. Ônibus da RMBH terão nova numeração. 2008. Disponível em: $<\mathrm{http}: / / \mathrm{www}$. transportes. mg.gov.br/leis/story/544-onibus-darmbh-terao-nova-numeracao $>$ Acesso em: 25 out. 2016

SILVA, D. Sistemas Inteligentes no transporte público por ônibus. 143 f. Dissertação (Mestrado em Engenharia de Produção) - Departamento de Engenharia de Produção, Universidade Federal do Rio Grande do Sul, Porto Alegre, 2000.

UNGER, R., CHANDLER, C.: A project Guide to UX Design: For User Experience Designers in the Field or in the Making. Second Edition.

Benkeley, C.A: New Riders, 2012

WRIGHT, Charles. Facilitando o transporte para todos. $1^{\mathrm{a}}$ ed. Washington, D.C. : Banco Interamericano de Desenvolvimento, 2001.
Realização:
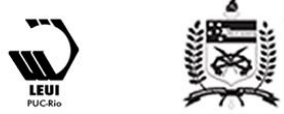